\title{
LA IMPLANTACIÓN INDUSTRIAL DE RENAULT EN ESPAÑA: LOS ORÍGENES DE FASA-RENAULT, 1950-1970*
}

\author{
ESTHER M. SÁNCHEZ SÁNCHEZ. \\ Instituto de Historia-CSIC
}

\begin{abstract}
RESUMEN
Este artículo estudia las dos primeras décadas de actividad industrial en España de la empresa francesa de automóviles Renault. El trabajo se inicia con un examen del proceso de negociaciones que desembocó en la concesión de la primera licencia de fabricación y en la constitución de la sociedad española concesionaria (FASA), cuyo capital fue enteramente suscrito por accionistas españoles. Durante sus primeros doce años de vida industrial, FASA creció a un ritmo sostenido, pero adoleció de importantes problemas de calidad y organización. Su verdadera expansión fue pareja al control de la sociedad matriz francesa, efectivo desde 1964. El artículo finaliza con la exposición de algunos de los factores explicativos del éxito de Renault en España, entre ellos la adaptación a los condicionantes del mercado local, la concesión de ciertos márgenes de gestión autónoma y la flexibilidad en materia de exportación.
\end{abstract}

Palabras clave: Renault, FASA, industria del automóvil, concesionarios.

\footnotetext{
Quiero expresar mi agradecimiento a las personas encargadas de la gestión de los archivos históricos de Renault en Billancourt y de FASA-Renault en Valladolid, por todas las facilidades prestadas para el acceso a los fondos que constituyen la base de este estudio. Agradecimiento que hago extensivo a los dos evaluadores anónimos de la Revista de Historia Económica, cuyos comentarios y sugerencias han sido de gran utilidad para mejorar el texto final. Los posibles errores o carencias son de mi exclusiva responsabilidad.

a Duque de Medinaceli 6, E28014 Madrid, España. esther@ih.csic.es
} 


\begin{abstract}
This article analyses the industrial activity of the French automobile company Renault during its first two decades in Spain. A first section examines the negotiations which concluded in the concession of the Spanish license and the establishment of a Spanish licensee society (FASA). A second part analyses the early years of FASA, in which it experienced a sustained growth overshadowed by product quality and management problems. We show how FASA's main phase of expansion coincided with the French head office's control, effective from 1964 on. The last part of the article summarizes some of the factors contributing to the success of Renault in Spain: such as adapting to local market conditions, establishing a certain degree of freedom in management and a more flexible export policy.
\end{abstract}

Keywords: Renault, FASA, automobile industry, licensee.

JEL Classification: N84, N64.

\title{
1.INTRODUCCIÓN
}

El fundador de la empresa francesa de automóviles Renault, Louis Renault, construyó su primer automóvil en Billancourt, a las afueras de París, en 1898. Diez años después fundó en Madrid su segunda filial de venta en el extranjero, después de la de Londres: la Sociedad Anónima Española de Automóviles Renault (SAEAR), que se encargó de importar los vehículos fabricados en Francia y comercializarlos en España a través de una red local de concesionarios, agencias y servicios de venta. La SAEAR mantuvo un crecimiento sostenido hasta los años treinta, en que comenzó a arrojar resultados progresivamente deficitarios. Actuaron en su contra la proliferación de barreras proteccionistas, la estrechez de la demanda y los altos precios de venta, factores que se agravaron en el contexto de la guerra civil española y de la segunda guerra mundial. Aunque la posibilidad de su liquidación fue examinada en varias ocasiones, Louis Renault optó por supeditar los beneficios de su filial española al mantenimiento de la marca y de la red comercial en España, a la espera de circunstancias más favorables que debían necesariamente presentarse algún día ${ }^{1}$. Durante estos años difíciles, la SAEAR compensó parte de sus pérdidas con la multiplicación de sus productos -tractores, autobuses, camiones, material de guerra, combustible, etc.- y de sus actividades -alquiler de vehículos, mercado de

${ }^{1}$ En una reunión celebrada en Billancourt el 28 de marzo de 1966, los dirigentes de Renault recordaban el leitmotiv de Louis Renault hacia España: «Cette situation ne peut pas durer et, en attendant qu'elle change, notre objectif est d'être présents». Reunión de la Dirección. Billancourt, 28/III/1966. Archives Renault, fonds Vernier-Palliez (V-P), caja 34. 
segunda mano, servicios de reparación y mantenimiento, etc. Esta política de diversificación aseguró la permanencia de la SAEAR y de la marca Renault en España hasta la década de los cincuenta, en la cual se consolidó la organización comercial, se introdujo la actividad industrial y, en definitiva, se puso en marcha una de las grandes empresas del automóvil en España ${ }^{2}$.

El propósito de este artículo es analizar la implantación industrial de Renault en España, un proceso que puede dividirse en dos etapas. La primera, de 1951 a 1964, corresponde a la gestión española de la producción de Renault en nuestro país. La segunda, de 1964 a 1970, marca el inicio de su subordinación a la casa matriz francesa. En una última sección se presentarán algunas de las claves del éxito de la implantación de la industria francesa en España, a través del caso concreto de una de sus exponentes más internacionales, la empresa de automóviles Renault.

\section{PRIMERAETAPA: LAINDEPENDENCIADE LASOCIEDAD ESPAÑOLA, 1951- 1964}

Al término de la guerra civil española, el Gobierno franquista promulgó una normativa autárquica, basada en el principio de sustitución de importaciones, para garantizar la independencia política y económica de España respecto al exterior. Convencido de que la motorización sería uno de los pilares del relanzamiento industrial del país, tomó medidas drásticas para acelerar el desarrollo de una industria nacional del automóvil: incremento sensible de las tarifas arancelarias y reducción al mínimo de los contingentes de importación de vehículos completos. Con ello, las grandes firmas exportadoras extranjeras intensificaron sus ofertas para instalar fábricas de montaje en España, en las que ensamblarían sus vehículos a partir de piezas sueltas -Completely Knocked Down, o CKD- o semisueltas-Semi Knocked Down, SKD-, en parte importadas y en parte fabricadas por la industria local. A finales de los años sesenta, cinco grandes constructores extranjeros se habían implantado en España: Fiat (1950), Renault (1951), Citroën (1957), Chrysler (1965) y British Motor Corporation (1966).

En los años cincuenta, Renault era una empresa pública. El Gobierno francés había decretado su nacionalización al término de la segunda guerra mundial, con el doble objetivo de impulsar su reconstrucción y castigar la colaboración de Louis Renault con el Tercer Reich durante la ocupación. Desde entonces, el Estado, único accionista, designó directamente a sus responsables, planificó su ejecutoria, le otorgó ayuda financiera y le atribuyó el papel de «empresa-piloto», esto es, la misión de mostrar a sus concurrentes el camino a seguir para la recuperación y

\footnotetext{
${ }^{2}$ Sobre los orígenes y evolución de la SAEAR, vid. Maison (1996) y Cebrián (2001).
} 
expansión de la nación francesa. Al abrigo del Estado y del contexto occidental de crecimiento, Renault, que pasó a denominarse Régie Nationale des Usines Renault (RNUR), experimentó un importante desarrollo, reflejado, entre otros aspectos, en su creciente expansión por Francia y el extranjero.

\subsection{La obtención de los permisos oficiales}

La iniciativa de construir una fábrica de montaje de vehículos Renault en España no fue francesa, sino española. En 1950, un grupo de industriales y hombres de negocios liderados por Manuel Jiménez Alfaro, coronel de artillería del Ejército, y por Nicolás Franco, hermano del Jefe del Estado y embajador en Lisboa, solicitó a la RNUR la concesión de una licencia para montar en España vehículos de marca Renault. Al mismo tiempo, el grupo presentó el proyecto a la Delegación de Industria de Valladolid, por considerar que esta localidad reunía una serie de ventajas que facilitarían la instalación inicial. En efecto, además de ser el lugar de residencia de buena parte de los integrantes del grupo, Valladolid contaba con naves susceptibles de ser utilizadas para establecer la primera fábrica de montaje, mano de obra abundante y relativamente cualificada, proximidad de centros abastecedores de materias primas, comunicaciones ferroviarias y personalidades locales interesadas en la iniciativa ${ }^{3}$. Pero la ejecución del proyecto dependía de la doble aprobación por parte del Gobierno español y de la empresa nacional francesa, algo complicado en unos años en los que, por motivos políticos e ideológicos, las relaciones francoespañolas pasaban por uno de sus momentos de mayor distanciamiento.

En una primera etapa, el grupo canalizó sus esfuerzos hacia la obtención de la licencia francesa. La reacción inmediata del presidente de la RNUR, Pierre Lefaucheux, fue rechazar toda idea de construir en España. Argumentó esta negativa señalando las dificultades financieras que acuciaban a su empresa y, sobre todo, su repulsa a trabajar con la plana mayor del régimen franquista ${ }^{4}$. En verdad, era un asunto complicado para un antiguo miembro de la Resistencia y compagnon de la Liberación de

\footnotetext{
${ }^{3}$ Desde finales del siglo XIX, importantes fábricas metalúrgicas, entre ellas la Compañía de Caminos de Hierro del Norte de España, la Sociedad Española del Carburador IRZ, Delibes S.L. y, más tarde, la propia RENFE, habían instalado talleres industriales en Valladolid y formado a varias generaciones de mecánicos. Vid. Gómez Mendoza (1990), Pastor, Delgado y Calderón (1992), Polo (1998), Catalán (2000) y Gimeno (2002). Entre estas personalidades se encontraba Santiago López González (sucesivamente concejal, alcalde y presidente de la Cámara de Comercio de Valladolid), que respaldó política y financieramente el proyecto, intuyendo, según sus propias declaraciones, «la importancia que para España tendría, en aquellos años cruciales, el montaje y luego fabricación propia de vehículos». Vid. Laredo (1983) y Represa y Garabito (1986).

${ }^{4}$ Informe de Jean Guillelmon, administrador-delegado de la SAEAR, 14/IX/1950. Archives Renault, Sécrétariat du Président-Directeur-Général (PDG), caja 75.
} 
París, al que el Gobierno francés había atribuido la responsabilidad de limpiar a Renault de su pasado filo-fascista. Lefaucheux topó, sin embargo, con la oposición de sus colaboradores y de varias personalidades influyentes en el seno de la RNUR, de la SAEAR y del propio Gobierno francés. Enseguida recibió todo un repertorio de razones que avalaban la concesión a España de la licencia de fabricación solicitada. Primero, dada la parquedad de los contingentes de importación de vehículos completos, la fabricación sobre el terreno sería la única manera de acceder al mercado español. La venta de piezas sueltas permitiría, además, disminuir los costes de producción de las fábricas francesas y, aunque se alcanzara un porcentaje de fabricación nacional del 100\%, hipótesis inviable en términos de rentabilidad, siempre quedarían los beneficios derivados del pago de licencias, técnicas y materiales. Por otra parte, en el caso de España confluían otra serie de ventajas a tener en cuenta: una implantación antigua, que garantizaba el conocimiento del mercado; una economía autárquica, que limitaba la competencia extranjera, y una mano de obra abundante, más barata y menos reivindicativa que la francesa. Para vencer la principal reserva del presidente -su repulsa a tratar con los jerifaltes de la dictadura-, se le indicó que ello facilitaría la obtención de los permisos oficiales necesarios para alimentar la cadena de piezas Renault, e incluso haría posible la importación de vehículos completos fuera de los contingentes bilaterales acordados. Se le insistió, finalmente, en el gran potencial de desarrollo de la economía española y, como señaló en su día el fundador, en la necesidad de estar presentes cuando se iniciase el despegue:

«[...] il est essentiel que nous soyons présents en Espagne, car c'est un marché sur lequel, après des périodes de «vaches maigres», des affaires intéressantes peuvent être réalisées à condition d'être sur place» ${ }^{5}$.

Lefaucheux acabó por dar la razón a sus colaboradores y aceptó el affaire español, aunque con la doble condición de no poner ni un franco en el proyecto (sic) y mantener el control de la venta en España a través de la SAEAR ${ }^{6}$.

Conseguido el acuerdo de la RNUR, el paso siguiente era obtener en España los diversos permisos oficiales que se exigían, en estos años de economía dirigida, para todo proyecto de implantación industrial, comercial o financiera. Nicolás Franco y, sobre todo, el coronel Jiménez Alfaro iniciaron entonces una laboriosa campaña destinada a obtener el mayor número posible de adeptos. Para ello, recorrieron despachos ministeriales, visitaron a industriales y banqueros, se entrevistaron con el embajador de Francia y solicitaron varias audiencias con Franco. Intentaron convencer a sus interlocutores de que los vehículos podrían ser rápidamente fabrica-

${ }^{5}$ Informe de Jean Guillelmon, 2/X/1950. Archives Renault, Sécretariat du PDG, caja 75.

${ }^{6}$ Informe de Jean Guillelmon, 18/X/1950. Archives Renault, Sécrétariat du PDG, caja 75. 
dos en España al 100\%, alcanzando cantidades, calidades y precios de venta análogos a los obtenidos en Francia. Por otra parte, insistieron en las posibilidades de exportación de los vehículos españoles hacia América Latina, un aspecto que, además de suponer un incentivo para convencer al Gobierno español, también atrajo a los dirigentes de la empresa francesa:

«La possibilité de disposer d'une industrie automobile exportatrice est en effet de nature à chatouiller l'amour-propre espagnol et ménager les susceptibilités [...] D'ailleurs, l'exportation de nos voitures comme espagnoles faciliterait grandement la vente sur certains marchés de l'Amérique du Sud» ${ }^{7}$.

El principal obstáculo a superar fue la férrea oposición del INI, que pensaba disponer del monopolio de la construcción de automóviles de turismo en España desde que, en 1950, la Sociedad Española de Automóviles de Turismo (SEAT) concluyera un acuerdo con la firma italiana FIAT para la fabricación con licencia de sus vehículos en España ${ }^{8}$.

El proyecto de implantación de Renault en España recibió la aprobación del Gobierno en el transcurso del Consejo de Ministros de 10 de octubre de $1951^{9}$. Según la documentación francesa, la filiación familiar de Nicolás Franco, el rango militar de Jiménez Alfaro y el optimismo de ambos en cuanto al porcentaje de fabricación nacional fueron factores decisivos para la obtención de los permisos españoles. Puede que la animadversión de los ministros de Comercio, Industria y Hacienda hacia el presidente del INI, Juan Antonio Suanzes, también influyera en la obtención del beneplácito del Consejo de Ministros. En cualquier caso, se trataba de un proyecto interesante para ampliar y renovar el maltrecho parque automovilístico español. Baste señalar que, en 1951, con una población que superaba los 28 millones de habitantes, España no alcanzaba los 200.000 vehículos operativos, de los que sólo una minoría eran turismos y la mayoría superaba los diez años de vida ${ }^{10}$.

\footnotetext{
${ }^{7}$ Informe de Jean Guillelmon, 6/II/1951. Archives Renault, Sécrétariat du PDG, caja 75.

${ }^{8}$ Sobre los orígenes de la SEAT, vid. San Román (1995a), (1995b) y (1999). La oposición del INI al proyecto Renault parece confirmar la tesis de que este holding público, con sus pretensiones monopolísticas y sus obstáculos a la iniciativa privada, actuó como un factor retardatario de la industrialización en España. Vid. López Carrillo (1998), San Román (1999), Gómez Mendoza (2000) y García Ruiz y Santos Redondo (2001). No obstante, en este caso las discrepancias del INI sólo consiguieron demorar el proyecto unos meses. No fueron suficientes para impedir su consecución ni para alterar de forma significativa el rumbo de Renault en España.

${ }^{9}$ La autorización oficial fue publicada en el $B O E \mathrm{n}^{\circ}$ 292, de 19 de octubre.

${ }^{10}$ Vid. Nicolau (1989, p. 71) y Gómez Mendoza (1989, p. 306), ambos en Carreras (ed.). Para más detalles sobre la situación de la industria del automóvil en España, vid. Blanco Losada (1960), De Lorenzo (1962), Manzanares López (1964), Merlo Calvo (1966), Bueno Lastra y Ramos Barrado (1981), Hernández Marco (1986), Ciuró (1994), López Carrillo (1998) y los reportajes incluidos en Amitié Franco-Espagnole (1962) y Entreprise (1968).
} 


\subsection{La creación de Fabricación de Automóviles S.A. (FASA)}

La autorización oficial anunciaba, por una parte, la constitución de una sociedad anónima de derecho español, con domicilio social en Madrid, que se encargaría de gestionar los procesos industriales de Renault en España, y, por otra parte, la instalación en Valladolid de una fábrica de montaje que alcanzaría una cadencia inmediata de 25 vehículos al día y un porcentaje de fabricación nacional -o «grado de nacionalización»- del 90 ó 100\% en el plazo de seis años. También notificaba el nombramiento de Nicolás Franco y de Jiménez Alfaro como mandatarios de la RNUR en España.

La formalización de los trámites legales y administrativos de la nueva sociedad batió un récord de rapidez. El objetivo era poder adscribirse a la antigua legislación sobre sociedades anónimas que, a partir del 1 de enero de 1952, habría de ser reemplazada por un régimen menos favorable a la participación extranjera. La nueva sociedad, denominada Fabricación de Automóviles S.A. (FASA), quedó constituida oficialmente el 29 de diciembre de 1951, con un capital social de 5 millones de pesetas $^{11}$.

Para la obtención de suscriptores del capital se barajaron diversas posibilidades. Hubo que descartar a los seis grandes bancos privados españoles que habían participado en la constitución del capital social de la SEAT: Hispano-Americano, Central, Español de Crédito, Urquijo, Bilbao y Vizcaya. Ninguno de ellos se mostró interesado en participar en la creación de una sociedad concurrente que sospechaban no iba a alcanzar el mismo grado de favor estatal que la SEAT ${ }^{12}$. Los proyectos que la RNUR examinó con mayor detenimiento fueron los presentados por dos grupos de empresarios: los dirigentes de la SEIDA, empresa especializada en la importación de vehículos pesados, y una asociación de hombres de negocios codirigida por B. Iban, miembro del Consejo de la SAEAR, y M. Smith, presidente de la Cámara de Comercio Americana en Madrid. En sendos viajes a Billancourt, ambos grupos declararon estar dispuestos a suscribir mayoritariamente el capital de la nueva sociedad, a condición de que la RNUR les cediera la exclusividad de la venta en España. Tras algunas vacilaciones, la empresa francesa acabó por recha-

\footnotetext{
${ }^{11}$ El capital fue fijado en 5 millones de pesetas para no tener que solicitar autorización al Ministerio de Hacienda, un trámite engorroso que sólo era indispensable si se superaba esta cifra. Con el acta de constitución en la mano, se procedió a elevar la cantidad inicial hasta los 60 millones de pesetas. Junta Extraordinaria, 12/1/1952.

${ }^{12}$ Efectivamente, de las tres iniciativas extranjeras aprobadas en el decenio de los cincuenta -FIAT, Renault y Citroën-, sólo FIAT-SEAT fue declarada «de interés nacional», con lo que adquirió la potestad de expropiación forzosa de terrenos, la exención de impuestos de hasta un $50 \%$, la rebaja de los derechos arancelarios y la preferencia en el acceso a los créditos y subvenciones oficiales. San Román (1999, p. 259).
} 
zar sus propuestas, puesto que consideraba imprescindible el mantenimiento de su filial comercial en el país. La SAEAR permitiría canalizar hacia Francia una parte importante de los beneficios de venta -de las importaciones francesas y de las fabricaciones españolas- $y$, al mismo tiempo, posibilitaría el ejercicio de un control indirecto sobre los procesos de producción que se llevaran a cabo al otro lado de los Pirineos.

Al final, fueron los industriales vallisoletanos promotores de la iniciativa los que, en asociación con algunos bancos locales -liderados por el Banco Castellano-, aceptaron financiar la fabricación de automóviles en España y reservar a Francia su comercialización. La RNUR había esperado arduas negociaciones, sobre todo desde que el INI denegara a FIAT la conservación de su antigua concesionaria de venta, la sociedad FIAT-Hispania, constituida en 1919. Para la empresa francesa, la rápida conclusión de la operación fue una prueba evidente de la falta de experiencia e ingenuidad de Nicolás Franco y Jiménez Alfaro:

«[...] ce naïf optimisme leur a inspiré une confiance absolue dans l'obtention de bénéfices très importants, alors que tout autre personne qui aurait accepté de prendre la responsabilité de la marche de la société constructrice aurait exigé le monopole de la vente comme contrepartie indispensable des risques de fabrication» ${ }^{13}$.

Tras la constitución de FASA, se firmó el contrato que establecía las condiciones para la producción y el montaje en España del primer vehículo Renault, el $4 \mathrm{CV}$. Según las cláusulas del contrato, la RNUR se comprometía a ceder las licencias de fabricación, la asistencia técnica y los equipos necesarios para el funcionamiento de la cadena de montaje. Permitía a la sociedad española adquirir libremente material en el mercado nacional o internacional, siempre que dicho material cumpliese ciertos requisitos de homologación técnica. También autorizaba la exportación a terceros países, a condición de ser previamente informada de los pormenores de cada operación. Por su parte, FASA entregaría a la RNUR un canon del 2,5\% sobre el precio de venta en España de cada vehículo, deducción hecha del valor de las piezas importadas y de las comisiones a agentes e intermediarios. También quedaba sujeta a no introducir ninguna modificación en los vehículos montados en España, a mantener en secreto la información suministrada y a permitir toda inspección de los agentes franceses delegados a tal efecto. Por último, el texto estipulaba que FASA controlaría las actividades industriales de Renault en España y que la SAEAR se encargaría de los servicios de venta y postventa. Respetando esta distribución, los dirigentes

\footnotetext{
${ }^{13}$ Informe de Jean Guillelmon, 21/1/1952. Archives Renault, Sécrétariat du PDG, caja 75.
} 
de ambas sociedades acordaron no inmiscuirse, salvo demanda expresa, en los asuntos internos de la otra parte ${ }^{14}$.

La primera fábrica de montaje de FASA se ubicó a las afueras de Valladolid, sobre un terreno de $35.000 \mathrm{~m}^{2}$ situado en la carretera de Madrid. Disponía de cinco líneas de montaje: la primera estaba destinada al ensamblaje de la carrocería, la segunda a su pintura, la tercera a la colocación de los órganos mecánicos, la cuarta al montaje del grupo moto-propulsor y la quinta al añadido final de los accesorios. En la factoría o centro de ensamblaje de Valladolid convergían elementos de fabricación nacional y extranjera. Durante sus primeros años de funcionamiento, las piezas de origen español -motores de la sociedad Nueva Montaña Quijano, carrocerías de la firma Cointra, cajas de cambios fabricadas por Industrias Subsidiarias de Aviación ISA, etc.- no superaban el $15-20 \%$, frente a un $80-85 \%$ de piezas de origen francés. Muchas de estas importaciones se realizaron entonces de forma dudosamente legal o fraudulenta, a fin de eludir las tasas aduaneras y el control de contingentes. En este sentido, pueden mencionarse operaciones como la domiciliación ficticia en Canarias o en las plazas africanas -en las cuales las tarifas aduaneras eran más bajas-, el uso indebido de adquisiciones con carácter temporal -para ferias y exposiciones- o la utilización abusiva de permisos de importación especiales -por cambio de residencia o de nacionalidad. En ocasiones, no hubo que recurrir a tales subterfugios, pues no faltaron funcionarios y altos responsables dispuestos, desde los ministerios o las corporaciones locales, a dispensar favores al mismísimo hermano mayor del Caudillo ${ }^{15}$.

\subsection{El lento despegue de la producción industrial}

Durante 1952, la actividad industrial de FASA permaneció en suspenso. La falta de divisas para comprar piezas a Francia y los problemas de calidad, cantidad y

\footnotetext{
${ }^{14}$ «Contrat pour la fabrication et le montage en Espagne de la 4 CV Renault», 31/12/1951. Archives Renault, Sécrétariat du PDG, caja 75. Con leves modificaciones, estas condiciones se aplicaron, durante los años siguientes, a otros modelos de la casa Renault fabricados en España: Dauphine (1958), Gordini (1961), Ondine (1962), Renault 4 (1963), Renault 8 (1965), Renault 10 (1966), Renault 6 (1969), Renault 12 (1969), Renault 5 (1972)..., además de vehículos industriales y de competición deportiva. Efectuada la aprobación conjunta de cada nuevo vehículo, FASA recibía la colección de piezas sueltas, un prototipo y la documentación y personal técnico necesarios para iniciar la producción. Cuando los controles de calidad, pruebas de homologación y ensayos en pista y carretera aportaban resultados satisfactorios, se iniciaba la fabricación en serie. Si, al principio, el lapso entre la presentación de los nuevos modelos en Francia y en España era de varios meses, a finales de los años sesenta se llegó a una sincronía casi perfecta. Vid. descripciones técnicas y reportajes gráficos de cada vehículo en el inventario Colección de Vehículos fabricados en España (2001) y en los números de la revista Rombo correspondientes a los años de lanzamiento.

15 Sánchez Soler (2001, pp. 90-91).
} 
plazos de entrega de las piezas nacionales impidieron la alimentación de la cadena de montaje. De esta forma, expiró la vigencia del acuerdo comercial hispano-francés de 1951-1952, al cual estaba acogida la autorización inicial, y hubo que cursar otro permiso de importación en el marco del nuevo acuerdo de 1952-1953. La producción industrial de Renault en España se inició en 1953. El 4 de junio llegaron los primeros vagones con las piezas procedentes de Francia y el 12 de agosto los once primeros 4 CV Renault ensamblados en la fábrica de FASA desfilaron por las calles de Valladolid, hasta el Ayuntamiento, donde tuvo lugar su presentación oficial a las autoridades locales ${ }^{16}$. A finales de 1953, la fabricación alcanzó 707 unidades, a la cadencia prevista de 25 al día. Durante los años siguientes, la producción evolucionó a un ritmo sostenido, de forma que en 1955 se superaron las 4.000 unidades, en 1959 las 8.000 y en 1961 las 15.000 .

El 4 CV, o «cuatro-cuatro» en la terminología local -4 caballos, 4 puertas-, que rodaba en España desde finales de los años cuarenta gracias a las importaciones de la SAEAR, gozaba de una buena imagen popular: «[...] es un coche de poco consumo, conducción ágil y sorprendente aptitud escaladora, muy adecuado para la accidentada geografía hispana» ${ }^{17}$. Los precios de venta al público del $4 \mathrm{CV}$ español eran sensiblemente superiores a los fijados en otros países para el mismo modelo, sobre todo teniendo en cuenta las diferencias salariales. Concurrían en el caso español la necesidad de amortizar los gastos de la fábrica de montaje y la existencia de una elevada presión fiscal ${ }^{18}$. Pero la penuria de automóviles en la España de los años cincuenta era tal que una fuerte demanda desbordó desde el principio la capacidad de FASA y llegó incluso a generar un mercado negro de reventa. En definitiva, el «cuatro-cuatro» fue bien acogido entre la población española y, aunque con cierto retraso, la producción industrial de FASA alcanzó la cadencia establecida en la autorización inicial, registrándose un crecimiento ininterrumpido durante los años siguientes.

Pero la dirección de la RNUR no estaba en absoluto satisfecha con los resultados. Dos problemas importantes oscurecían, hasta casi apagar, los resultados anteriores: la mala calidad de los vehículos ensamblados en la factoría vallisoletana y las irregularidades en la gestión de la sociedad española. Varios controles de calidad

${ }^{16}$ Vid. reportaje en El Norte de Castilla. Diario de Valladolid, 13/8/1953.

${ }^{17}$ El Alcázar (1952), Cfr. Gordo (1995, pp. 27-28). Sobre la historia y características técnicas del 4 CV, véanse Fridenson (1986) y (1997), Polo (1998), Latouille y Felten (1999) y Gimeno (2002).

${ }^{18}$ Superando, con mucho, al de otros países europeos, el régimen fiscal aplicado al automóvil en España -impuesto de lujo, impuesto sobre la gasolina, tasa municipal de circulación, gastos de matriculación, etc.- cubría, por sí sólo, cerca de un 20\% de los ingresos de la Hacienda Pública española. Se trataba, además, de un régimen poco equilibrado, puesto que aplicaba el mismo tipo de gravamen cualquiera que fuese el estado, la calidad y la clase del vehículo -utilitario, deportivo o de lujo-, distinguiendo únicamente la potencia. 
efectuados por los técnicos de Billancourt habían demostrado las deficiencias de las piezas y accesorios de fabricación española. Además, la producción de FASA se había revelado incapaz de satisfacer la demanda interna y de garantizar un stock mínimo en los establecimientos de venta y postventa. Esta situación se agravaba con los continuos retrasos y los altos precios demandados por las industrias locales auxiliares de FASA, en su mayoría con un nivel muy bajo de desarrollo y caracterizadas por la pervivencia de estructuras familiares, equipos obsoletos y procesos semiartesanales. Año tras año, la RNUR solicitó al Ministerio español de Comercio el incremento de los contingentes de importación de vehículos completos o, al menos, de las licencias para importar piezas sueltas de Francia. Pero las autoridades españolas demostraron no estar dispuestas a disminuir, sino todo lo contrario, los porcentajes de fabricación nacional ${ }^{19}$.

El asunto de la gestión era aún más preocupante para la dirección de la RNUR. Según Lefaucheux, la sociedad española funcionaba en condiciones deplorables, dirigida por un par de oportunistas que no poseían ninguna experiencia, que carecían de las nociones más elementales sobre cuestiones administrativas, financieras, industriales y comerciales, y que envenenaban la atmósfera con discusiones bizantinas sobre los temas más extravagantes y alejados de la fabricación de automóviles ${ }^{20}$. Nicolás Franco y Jiménez Alfaro, en su momento útiles para la obtención del permiso de fabricar en España, se habían convertido, en opinión del director francés, en una mezcla de pesos muertos, por su incompetencia, y de elementos peligrosos, por sus malas relaciones con el resto de accionistas y su obstinación en cortar el cordón umbilical con la RNUR. Lefaucheux se preguntaba si no tendrían que haber aceptado la condición de ceder la exclusiva de la venta en España para asegurarse la entrada de hombres de negocios inteligentes, experimentados y con los pies en la tierra ${ }^{21}$. Las relaciones no podían ser más tensas. Por su parte, Nicolás Franco y Jiménez Alfaro acusaban a la RNUR de querer sabotear la fabricación en España para exportar el mayor número posible de productos franceses, de querer limitar los beneficios de FASA para incrementar los de la RNUR y, en definitiva, de meterse donde nadie les llamaba ${ }^{22}$.

El presidente de la RNUR había olvidado sus reservas iniciales y había apostado, junto con sus colaboradores, por las ventajas y el potencial económico del país vecino. Pero consideraba que, con estos preliminares, FASA estaba abocada al fracaso. Ello llevaría aparejado el cierre del mercado español a los productos Renault

${ }^{19}$ Discusiones previas a la renovación del acuerdo comercial bilateral, en el Archivo del Ministerio francés de Economía, Finanzas e Industria (AMEFI-F), Direction du Commerce Extérieur: Espagne, B-55150.

${ }^{20}$ Reunión de la Dirección. Billancourt, 13/9/1953. Archives Renault, fonds V-P, caja 34.

21 Ibidem.

${ }^{22}$ Informe de Jean Guillelmon, 8/12/1952. Archives Renault, Sécrétariat du PDG, caja 75. 
y la desacreditación de la marca en España, algo que costaría bastante remediar a medio plazo. Lefaucheux reconsideró su determinación de «no poner ni un franco en el proyecto». Sólo el ejercicio de un control directo sobre FASA permitiría gestionarla «a la francesa» y frenar el desastre de la gestión «a la española» ${ }^{23}$. Para ello, era necesario disponer de una presencia importante en su Consejo de Administración, que sería directamente proporcional al porcentaje de capital social suscrito. Desde entonces, la RNUR aprovechó las ampliaciones del capital de FASA para intentar adquirir un porcentaje importante de acciones. Misión imposible: por un lado, la legislación española vigente limitaba al 25\% la participación extranjera en empresas españolas; por otro, los accionistas fundadores se habían reservado no sólo el derecho de suscribir o ceder las nuevas acciones, sino, además, la percepción de primas en dinero o en especie si lo hacían. El control de FASA continuaría, pues, en manos españolas y el tándem Franco-Jiménez Alfaro conservaría un puesto importante en sus órganos de gestión.

A finales de los años cincuenta, cuatro de los quince puestos del Consejo de Administración de FASA habían sido ocupados por miembros de la SAEAR, con lo que la RNUR había ampliado sus márgenes de control sobre la producción española. También había adquirido participaciones en el capital social de algunos de los principales suministradores locales de FASA: por ejemplo, el 15\% de Fabricación de Carrocerías S.A. (FACSA) o el 85\% de Fabricaciones Mecánicas S.A. (FAMESA). Pero el propósito de la sociedad francesa era sentar a sus propios accionistas en el Consejo de Administración de FASA.

\section{SEGUNDA ETAPA: EL CONTROL DE LA SOCIEDAD MATRIZ FRANCESA, 1964-1970}

Con la apertura de fronteras y la liberalización comercial derivadas de la creación de la CEE, Renault intensificó sus esfuerzos de implantación en el extranjero, centrándose, sobre todo, en los países en vías de desarrollo que, como España, garantizaban una reserva abundante y barata de mano de obra, importantes beneficios en concepto de asistencia técnica, y una mayor rentabilidad a medio y largo plazo. En España, tras la aplicación del Plan de Estabilización de 1959 y el ingreso en algunas de las principales organizaciones económicas internacionales -FMI, OECE, BIRD-, se asistió a una progresiva liberalización de la economía y, con ello, a una afluencia creciente de productos, técnicas y capitales foráneos. La nueva legislación española allanó el camino al establecimiento y ampliación de industrias extranjeras, a la par que suavizó las condiciones para la repatriación de beneficios. En el sector automo-

${ }^{23}$ Reunión de la Dirección. Billancourt, 8/3/1954. Archives Renault, Sécrétariat du PDG, caja 75 . 
vilístico, se liberalizaron los intercambios de piezas sueltas, accesorios y recambios, si bien la importación de vehículos completos permaneció sujeta durante largo tiempo al doble sistema de protección arancelario y de contingentes ${ }^{24}$. En el marco del Primer Plan de Desarrollo (1964-1967), Valladolid fue designada «Polo de Desarrollo Industrial», debido sobre todo a la existencia previa de una apreciable actividad industrial en la zona ${ }^{25}$. Con ello, sus industrias adquirieron beneficios similares a los otorgados a las «industrias de interés preferente»: expropiación forzosa de terrenos, reducción de impuestos, libertad de transferir beneficios, y preferencia en la obtención de subvenciones y créditos oficiales ${ }^{26}$. La confluencia de esta serie de condiciones contribuyó a acrecentar el interés de Renault hacia España y, más concretamente, hacia Valladolid.

En esta nueva etapa, la presidencia de la RNUR había sido conferida a Pierre Dreyfus, tras el fallecimiento de Pierre Lefaucheux en accidente automovilístico. Dreyfus nunca manifestó las reticencias de su predecesor a invertir en la España franquista. Tenía una visión más realista de la cuestión española, tanto por su propio conocimiento del país -había vivido y trabajado en España-, como por su sentido más práctico de las relaciones internacionales, que le llevaba a minimizar la dimensión ideológica:

«Si proche que je sois des Espagnols, je n'ai jamais été suspect de sympathie à l'égard du régime franquiste. Mais je partage l'opinion de beaucoup d'Espagnols selon laquelle la modernisation de l'économie du pays est la condition essentielle, puisqu'elle entraînera la libéralisation politique.» ${ }^{27}$

\subsection{El trasvase de acciones de España a Francia}

Desde 1958, una institución financiera española, el Banco Ibérico, había adquirido el control mayoritario de FASA, y su representante, Arturo Fierro, ostentaba el cargo de vicepresidente ${ }^{28}$. Nicolás Franco y Jiménez Alfaro continuaban formando parte del Consejo de Administración: el primero como presidente y el segundo como

\footnotetext{
${ }^{24}$ Sobre el proceso de liberalización de los intercambios, véase Viñas et al. (1979, vol. 3).

${ }^{25}$ Fernández Arufe y Pedrosa Sanz (1982, p. 131).

${ }^{26}$ Decreto $n^{\circ} 153 / 1964$ de 20 de enero.

${ }^{27}$ Dreyfus (1981, pp. 143-144).

${ }^{28}$ Junto al Banco Ibérico, el Banco de Santander mantuvo, durante algunos años, una participación importante en FASA, conseguida gracias a su estrecha vinculación con la firma siderúrgica cántabra Nueva Montaña Quijano S.A. Los trabajos de Gimeno (1993) y (2002) señalan que la desvinculación del banco de la familia Botín se habría producido hacia 1961, cuando FASA redujo sus pedidos de motores a Nueva Montaña Quijano en beneficio de FAMESA.
} 
vocal y asesor del presidente. Nicolás Franco había comunicado a la Dirección de la RNUR su descontento ante esta nueva situación, que reducía considerablemente sus márgenes de maniobra en la empresa. Sin querer dar la razón a su interlocutor pero, a la vez, tratando de no avivar sus recelos, Pierre Dreyfus se había limitado a responder que las acciones de FASA cotizaban en bolsa, por lo que cualquiera podía adquirirlas, y que Arturo Fierro había sido designado vicepresidente por un Consejo de Administración en el que la RNUR no poseía ningún representante directo $^{29}$. En el fondo, el presidente francés aprobaba este cambio, puesto que lo consideraba como un preludio del desplazamiento de Nicolás Franco y de Jiménez Alfaro desde la dirección efectiva hasta un simple lugar de honor en la sociedad española ${ }^{30}$.

El 17 de julio de 1964, Arturo Fierro dirigió a Pierre Dreyfus una carta personal en la que solicitaba, por un lado, la participación accionarial de la RNUR en FASA y, por otro, la integración de las actividades de venta y fabricación en una única sociedad. La misiva finalizaba advirtiendo que la negativa de la RNUR acarrearía una revisión inmediata, con posibilidad de suspensión, del programa de fabricación del Renault 8 (R-8), que había sido aprobado el año anterior ${ }^{31}$. ¿Cuáles fueron los detonantes de esta decisión? En primer lugar, el grupo de Arturo Fierro había soportado un gran esfuerzo financiero para el equipamiento de FASA, puesto que la autofinanciación -reservas y beneficios- y los fondos ajenos -emisión de obligaciones y crédito oficial-apenas habían cubierto la mitad de los gastos de inversión. A ello se sumaba el hecho de que buena parte de los accionistas, conscientes de las divergencias entre RNUR y FASA, habían manifestado su escepticismo ante el futuro de la sociedad española e incluso insinuado la posibilidad de retirar sus capitales. No era la primera vez que Arturo Fierro expresaba sus preocupaciones a Pierre Dreyfus, pero nunca lo había hecho de forma tan tajante. La gota que colmó el vaso pudo ser la estimación de los costes de fabricación y comercialización del citado R-8. Poco importaba el trasvase de poder a manos francesas: Arturo Fierro necesitaba ayuda.

La carta de respuesta de Pierre Dreyfus, fechada el 27 de julio, se iniciaba con tres afirmaciones rotundas: la primera, que la RNUR no negociaba bajo la amenaza; la segunda, que la fabricación del R-8 no era vital para la RNUR, pero sí lo era para FASA; y la tercera, que si la RNUR no se había implicado más en España era porque FASA se lo había impedido. Al final de su escrito, Dreyfus admitía, en un tono más calmado, que estaba dispuesto a estudiar ciertas modificaciones, por pura buena voluntad y porque existía, efectivamente, un problema en la organización de FASA ${ }^{32}$. Recordando el incidente, Pierre Dreyfus confesaría a sus colaboradores unos me-

\footnotetext{
${ }^{29}$ Carta de Pierre Dreyfus a Nicolás Franco, 22/3/1959. Archives Renault, fonds V-P, caja 34

${ }^{30}$ Reunión de la Dirección. Billancourt, 25/4/1961. Archives Renault, fonds V-P, caja 34.

${ }^{31}$ Carta de Arturo Fierro a Pierre Dreyfus, 17/7/1964. Archives Renault, fonds V-P, caja 34.

${ }^{32}$ Carta de Pierre Dreyfus a Arturo Fierro, 27/7/1964. Archives Renault, fonds V-P, caja 34.
} 
ses más tarde que tomó en serio las amenazas de Arturo Fierro y que no podía arriesgar el programa de fabricación del R-8, si quería que la RNUR conservase su posición y reputación en España ${ }^{33}$.

En realidad, se trataba de una oportunidad excelente para hacerse con el control de FASA y consumar lo que a Lefaucheux le fue imposible en los años cincuenta. Pese a sus problemas financieros internos, la RNUR adquirió inmediatamente el 49,9 \% del capital social de FASA, es decir, el máximo autorizado por la legislación española vigente a partir de $1959^{34}$. En el contrato, firmado el 30 de octubre de 1964, se recogía la prioridad de la RNUR en las futuras ampliaciones del capital social de FASA. Tras varias gestiones con el Ministerio de Industria, en las que Arturo Fierro actuó de intermediario, se consintió que la participación francesa en FASA se incrementara progresivamente hasta alcanzar casi un 75\% al cabo de diez años. Es cierto que, en muchos sectores industriales, la autorización ministerial necesaria para rebasar el 50\% de participación extranjera se obtuvo en la práctica con relativa frecuencia. Pero la anuencia oficial no fue tan común en lo que a la industria automovilística se refiere. Desde finales de los años cincuenta, la nueva legislación franquista había incitado a otras empresas extranjeras constructoras de automóviles a ampliar sus porcentajes de participación en el capital social de sus concesionarias españolas. No obstante, aparte de Renault, sólo se autorizó a la italiana FIAT y a la norteamericana Chrysler a superar el 50\% de sus participaciones respectivas en SEAT y en Barreiros Diesel. Es más, con el argumento de que el total de producción de las firmas instaladas cubría ampliamente las necesidades de la demanda, el Gobierno restringió el acceso al mercado español de otros grupos extranjeros, como Ford, Volkswagen o Peugeot, que vieron denegadas todas las demandas de implantación efectuadas en el transcurso de los años sesenta ${ }^{35}$.

La segunda aspiración de Arturo Fierro, esto es, la integración de las actividades industriales y comerciales, se hizo efectiva en el mismo contrato. FASA y la antigua SAEAR -que en 1962 había adquirido el apelativo de RESA, siglas de Renault España S.A.- se fusionaron en una única sociedad: FASA-Renault S.A. En realidad, esta unificación había venido barajándose desde 1960-1961, pero no interesó hacerla efectiva durante unos años en los que, con la extraordinaria expansión de la economía española, ambas sociedades obtenían beneficios sustanciales. Después, con la estabilización del crecimiento, se antepuso la necesidad de aligerar cargas fiscales y facilitar la coordinación.

\footnotetext{
${ }^{33}$ Nota de Pierre Dreyfus, 1/12/1964. Archives Renault, fonds V-P, caja 34

${ }^{34}$ Decreto-Ley 16/1959, de 27 de julio, sobre inversión de capital extranjero en empresas españolas.

${ }^{35}$ Las restricciones a la participación extranjera en la industria del automóvil no se relajaron hasta 1972, año en el que se suavizaron los requisitos para la autorización de nuevos constructores y el sector fue declarado «de interés económico y social preferente» (Decreto 3.757/1972, de 23 de diciembre).
} 
Después del trasvase de acciones, la gestión de FASA y, en general, la definición de la política de Renault en España fue encomendada a la Dirección Comercial de Exportación de la RNUR; más concretamente, a la Subdirección Comercial para América Latina y la Península Ibérica. Allí se fijarían, entre otras cuestiones, los programas de fabricación, costes, financiación, asistencia técnica y personal. Franceses y españoles acordaron reservar la presidencia de FASA a uno de los miembros españoles del Consejo de Administración. La RNUR dispondría, no obstante, de un representante permanente en el seno de la Dirección General de FASA, que se encargaría de vigilar la ejecución de los contratos y de garantizar la defensa de los intereses franceses en la Asamblea General, el Consejo de Administración y el Comité Ejecutivo de la sociedad española ${ }^{36}$. De todo ello daría cuenta en un minucioso informe enviado todos los meses a la RNUR. Por otra parte, los miembros franceses del Consejo de Administración de FASA y los jefes de otros servicios interesados constituyeron en Billancourt un grupo denominado «Comité Espagne», cuyo cometido era reunirse durante la quincena precedente a cada sesión del Consejo de Administración - unas cuatro veces al año- para emitir recomendaciones sobre las líneas de actuación de la RNUR en España.

\subsection{Efectos de la intervención francesa}

La entrada de capital francés en FASA se tradujo en importantes inversiones comerciales e industriales. Entre los años 1965 y 1970, se duplicó el número de establecimientos oficiales de venta y postventa -de 260 a 545-, y la producción pasó de 47.411 unidades a 98.695, a una cadencia diaria de 250 y 350 unidades respectivamente. Las matriculaciones de vehículos Renault en Península y Baleares -importaciones incluidas- se incrementaron de 182.839 a 421.728 , y las ventas de FASA-Renault -exportaciones incluidas-, de 47.109 a 101.219. La cifra de negocios y los beneficios de FASA también experimentaron un crecimiento importante durante el mismo intervalo: de 2.950 a 9.894 millones de pesetas, y de 193 a 521

\footnotetext{
${ }^{36}$ La representación francesa en la Dirección General de FASA fue atribuida a Pierre Semerena. A partir de 1964, la composición del Consejo de Administración quedó distribuida del siguiente modo: presidente, Nicolás Franco; vice-presidentes, Arturo Fierro y Michel Maison; consejero-secretario, Santiago López González; consejeros-gerentes, José Luis RodríguezPomatta y Pierre Semerena; vocales, Manuel Jiménez Alfaro, Alfonso Sánchez Huertas, Francisco Toda de Diezma, Luis Rodríguez Viña, Basilio Freire-Caeiro, Christian Beullac, René Meesemaecker, René Poilleux y Pierre Vernay. Esta composición se mantuvo hasta 1970, salvo en lo que respecta a la sustitución de Nicolás Franco por Arturo Fierro en la presidencia. Nicolás Franco fue nombrado presidente de honor y Michel Maison ocupó en exclusividad el cargo de vicepresidente.
} 
millones de pesetas, respectivamente. Como resultado, el total de dividendos y royalties percibidos por la RNUR pasó de 8.183 millones de francos en 1965 a 83.372 en $1970^{37}$.

\section{GRÁFICO1}

EVOLUCIÓN DE LAPRODUCCIÓN DE FASA-RENAULT, 1953-1970

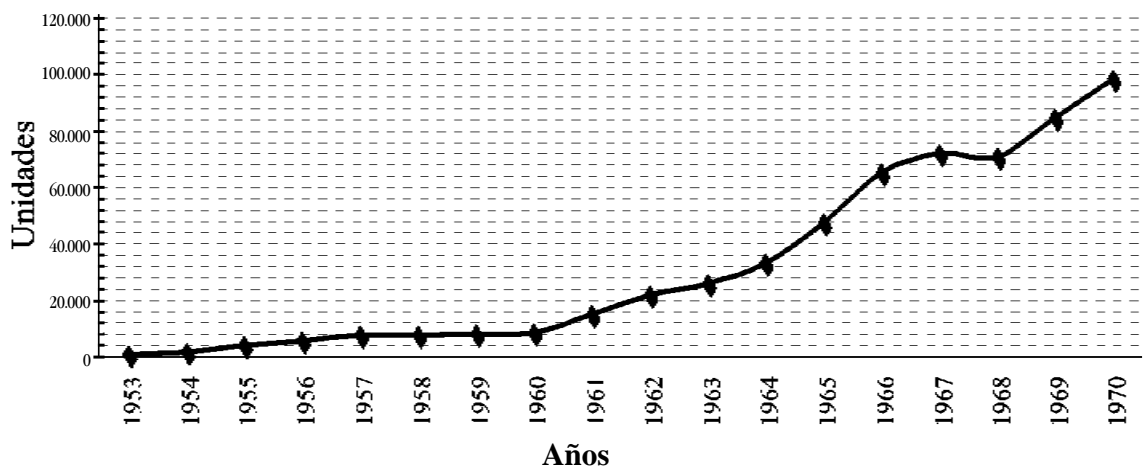

Fuente: Memorias y balances de FASA-Renault, 1953-1970

Desde 1964, las instalaciones de la cadena de montaje inicial fueron sucesivamente ampliadas y modernizadas. Con el fin de aminorar costes, se procedió a integrar en el mismo complejo industrial la fabricación de algunos de los principales elementos constituyentes de los vehículos. De esta forma, en noviembre de 1965, se inauguraron en Valladolid dos nuevas factorías: la de la sociedad FACSA, en la que se embutirían piezas de carrocería, y la de FAMESA, encargada de la fabricación de motores y órganos mecánicos de dirección y suspensión. Unos meses más tarde, FASA adquirió el activo que la sociedad ISA tenía invertido en la fabricación de cajas de velocidades. Con ello, tres de las principales subcontratistas de Renault en España quedaban integradas en el complejo vallisoletano de FASA. En 1968 se

${ }^{37}$ Cifras recogidas en la publicación Memoria y Balance de FASA-Renault, años 1965-1970. Archivo Histórico Provincial de Valladolid (AHPV), sección FASA-Renault, caja 9. Sin duda, la presentación de cuadros y gráficos completos para el período 1953-1970 permitiría apreciar mejor estos avances. Lamentablemente, la documentación consultada no ha proporcionado datos suficientes para elaborarlos, exceptuando el capítulo de la producción: véanse cuadros 1 , y 2 y gráfico 1. 
constituyó una sociedad para financiar la venta a plazos -Renault Financiaciones S.A.-, al tiempo que se inauguraban una nueva fábrica de motores, una pista de pruebas y un departamento de estudios. Cuatro años más tarde, se construyó una segunda fábrica de montaje en Valladolid y, un año después, se puso en marcha la tercera en la provincia de Palencia ${ }^{38}$. En definitiva, las instalaciones de Renault, reconocidas universalmente por una decoración homogénea y un logotipo -el rombo-, se expandieron por la geografía ibérica. Importantes personalidades francesas y españolas, algunas ajenas al mundo industrial, solían acudir a cada nueva inauguración. En sus discursos presentaban el caso de Renault como una de las mejores muestras del estrechamiento de relaciones entre ambos países ${ }^{39}$.

\section{CUADRO 1}

DETALLE DE LAPRODUCCIÓN DE FASA-RENAULT, 1953-1972

\begin{tabular}{|l|c|c|c|}
\hline \multirow{2}{*}{ Modelos } & \multicolumn{2}{|c|}{ Producción } & \multirow{2}{*}{ Total } \\
\cline { 2 - 3 } & Inicio & Fin & undades \\
\hline 4CV & 1953 & 1959 & 26.298 \\
Dauphine & 1958 & 1964 & 41.872 \\
Gordini & 1961 & 1967 & 44.861 \\
Ondine & 1962 & 1965 & 39.179 \\
Alpine & 1963 & 1978 & 1.904 \\
Renault-4 TL & 1963 & 1989 & 403.213 \\
Renault-4 F & 1963 & 1991 & 396.704 \\
Renault-8 & 1965 & 1976 & 266.331 \\
Renault-10 & 1966 & 1971 & 37.419 \\
Renault-6 & 1969 & 1986 & 338.357 \\
Renault-12 & 1969 & 1983 & 455.006 \\
Renault-5 & 1972 & 1984 & 983.118 \\
\hline
\end{tabular}

Fuente: FASA-RENAULT (2001): Colección de vehículos fabricados en España. Valladolid: Centro Patrimonial.

\footnotetext{
${ }^{38}$ Vid . descripción detallada de las instalaciones de Renault en España en Renault Magazine 22 (1959), 75 (1972) y 89 (1980), así como en los números de la revista Rombo correspondientes a los años de inauguración.

${ }^{39}$ Durante los años sesenta, las instalaciones de FASA-Renault se convirtieron en una escala obligada en los viajes oficiales de personalidades francesas a España, como lo atestiguan los programas conservados en los archivos históricos de los ministerios de asuntos exteriores de ambos países.
} 
La producción de FASA cubrió en torno al 20-25\% del mercado español -el «campeón nacional», SEAT, acaparó el 60\%, mientras que los otros constructores se repartieron el resto. La demanda creció a un ritmo constante, con un breve paréntesis registrado en 1967 a causa de las medidas de austeridad adoptadas por las autoridades españolas ante la recesión económica general. La amortización del capital invertido, la ampliación de las series de fabricación y la reducción de la presión fiscal determinaron la estabilización de los precios, que, no obstante, permanecieron por encima del promedio europeo. El desarrollo económico del país llevó aparejado el incremento de la renta per cápita y, con ello, el acceso al automóvil de estratos sociales cada vez más amplios. Además, el crecimiento de la producción permitió aplicar en España la política de venta a colectividades que Renault utilizaba con frecuencia en Francia. En este sentido, las ventas experimentaron una sensible mejoría con el suministro a entidades como el Ejército, las delegaciones ministeriales y las fuerzas armadas norteamericanas establecidas en España ${ }^{40}$.

Los trabajos realizados en nuestro país contaron con una importante asistencia técnica francesa de variada índole: cesión de conocimientos -patentados o no-, servicios de ingeniería, asesoramiento en gestión y administración, formación y capacitación del personal, suministro de información técnica, etc. ${ }^{41}$. Ello se tradujo en un continuo afluir de ingenieros y técnicos franceses a España, a la par que personal español acudía a las instalaciones de la RNUR en Francia. Todos los años se organizaban cursos de formación y especialización a uno y otro lado de los Pirineos. Al personal obrero se le enseñaban nuevas técnicas para la mejora de la productividad y de las condiciones de trabajo; al personal directivo, nuevos métodos de gestión y administración empresarial, en gran parte importados de Estados Unidos por las Misiones francesas de Productividad que habían visitado las fábricas norteamericanas en los años cincuenta ${ }^{42}$. Como contrapartida a las prestaciones técnicas recibidas, los gastos de estancia y desplazamiento del personal que la RNUR facilitase o admitiese en sus fábricas corrían mayoritariamente a cargo de $\mathrm{FASA}^{43}$. En estos años, a las necesidades de la industria española en materia de asistencia técnica se sumó la buena disposición de los expertos franceses para viajar a España. En palabras del Director de Personal de la RNUR, «l'Espagne est un

\footnotetext{
${ }^{40}$ «Compte-rendu du voyage a Madrid du 27 septembre au 1 octobre 1961». Michel Maison a Pierre Dreyfus, 10/10/1961. Archives Renault, fonds V-P, caja 34.

${ }^{41}$ Vid. relación de contratos de asistencia técnica autorizados por el Ministerio de Industria en la revista mensual Economía Industrial, publicada por la Secretaría General Técnica del Ministerio de Industria desde octubre de 1963.

${ }^{42}$ Barjot (2002)

${ }^{43}$ Desde 1958, un organismo estatal, la Association pour l'Organisation des Stages dans l'Industrie Française (ASTEF) asumió una parte importante de los gastos de los cargos directivos extranjeros enviados a Francia.
} 


\section{CUADRO 2}

EVOLUCIÓN DE LAPRODUCCIÓN DE AUTOMÓVILES EN ESPAÑA, 1953-1970 (vehículos industriales + vehículos de turismo)

\begin{tabular}{|c|r|r|r|r|r|r|l|}
\hline Año & $\begin{array}{c}\text { AUTHI- } \\
\text { BMC }\end{array}$ & $\begin{array}{c}\text { Chrysler- } \\
\text { Barreiros }\end{array}$ & $\begin{array}{c}\text { Citroën- } \\
\text { Hispania }\end{array}$ & $\begin{array}{c}\text { FASA- } \\
\text { Renault }\end{array}$ & $\begin{array}{c}\text { SEAT- } \\
\text { Fiat }\end{array}$ & $\begin{array}{c}\text { Total } \\
\text { nacional }\end{array}$ & $\begin{array}{c}\text { FASA- } \\
\text { Renault } \\
\text { (\% del total) }\end{array}$ \\
\hline 1953 & - & - & - & 707 & 1.345 & 3.221 & $21,9 \%$ \\
1954 & - & - & - & 1.643 & 2.551 & 6.478 & $24,4 \%$ \\
1955 & - & - & - & 4.050 & 7.641 & 16.159 & $25,1 \%$ \\
1956 & - & - & - & 5.533 & 10.502 & 22.155 & $24,9 \%$ \\
1957 & - & - & - & 7.540 & 14.353 & 30.385 & $24,8 \%$ \\
1958 & - & - & 401 & 7.824 & 22.157 & 40.178 & $19,5 \%$ \\
1959 & - & - & 1.692 & 8.239 & 28.440 & 45.721 & $18,0 \%$ \\
1960 & - & - & 3.486 & 8.407 & 31.116 & 51.428 & $16,3 \%$ \\
1961 & - & - & 6.259 & 15.158 & 36.596 & 66.298 & $22,9 \%$ \\
1962 & - & - & 12.319 & 22.083 & 40.483 & 75.766 & $29,1 \%$ \\
1963 & - & - & 19.146 & 25.798 & 47.313 & 94.038 & $27,4 \%$ \\
1964 & - & - & 25.960 & 33.341 & 76.161 & 135.657 & $23,3 \%$ \\
1965 & - & 1.000 & 39.800 & 47.411 & 91.006 & 178.132 & $26,6 \%$ \\
1966 & 27 & 49.559 & 43.404 & 65.287 & 123.286 & 280.762 & $23,2 \%$ \\
1967 & 14.645 & 31.523 & 36.739 & 72.349 & 160.657 & 315.911 & $22,9 \%$ \\
1968 & 15.621 & 33.756 & 40.113 & 70.870 & 180.007 & 345.874 & $20,5 \%$ \\
1969 & 16.089 & 36.838 & 36.443 & 84.862 & 222.218 & 397.450 & $21,3 \%$ \\
1970 & 17.821 & 37.173 & 41.228 & 98.695 & 283.681 & 479.347 & $20,6 \%$ \\
\hline
\end{tabular}

Fuente: Elaboración propia a partir de las memorias y balances de FASA-Renault, 1953-1970. Las cifras difieren ligeramente de las publicadas por la Secretaría General Técnica del Ministerio de Industria, Instituto Nacional de Estadística y Jefatura Central de Tráfico.

pays où les cadres et ingénieurs français ne réfusent jamais d'aller» ${ }^{44}$. En efecto, por encima de su régimen político o de su retraso económico, en España confluían aspectos interesantes como la proximidad geográfica, las afinidades de lengua y cultura y las posibilidades turísticas.

La expansión de las instalaciones implicó un importante incremento de la plantilla de personal. De 1964 a 1970 los efectivos totales de Renault en España pasaron

\footnotetext{
${ }^{44}$ Nota de la Dirección de Personal, 4/6/1959. Archives Renault, fonds V-P, caja 34.
} 
de 1.362 a 10.367 empleados, de los que más de 4.000 fueron incorporados entre 1965 y 1966. FASA se convirtió en el principal empleador industrial de toda la región castellana y, sobre todo, de la provincia de Valladolid, de donde procedía el grueso de los trabajadores. En los años sesenta, la mano de obra se componía esencialmente de obreros no cualificados (70\%), de origen rural (65\%) y con una edad comprendida entre los 24 y los 38 años (90\%). Con el tiempo, se ampliaron los porcentajes correspondientes al personal cualificado, de origen urbano y descendiente de los trabajadores que ocupaban o habían ocupado un puesto en la empresa. Aparte de crear trabajo en sus propios establecimientos industriales y comerciales, FASA generó un volumen importante de empleo indirecto por toda la geografía peninsular -sobre todo en Madrid y Cataluña-, gracias a la compra de bienes y servicios a empresas auxiliares involucradas, de alguna forma, en la fabricación de automóviles -desde la industria de transformación del metal a los servicios de transporte, publicidad o limpieza ${ }^{45}$.

FASA trasladó a España algunas de las condiciones laborales y prestaciones sociales aplicadas en Francia por la RNUR, en la medida, claro está, en que fueron compatibles con la legislación franquista: cuarta semana de vacaciones pagadas desde 1963, espacios de ocio en la empresa, facilidades para la adquisición de viviendas, asistencia médica, etc ${ }^{46}$. En uno de sus informes, la filial española señalaba que sus trabajadores podían congratularse de pertenecer al grupo de los mejor retribuidos de España: en 1965 su salario medio superaba en un 30-40\% al de otros operarios industriales de Valladolid. Además, la mayor parte del personal -obrero, subalterno, administrativo y técnico- se organizaba en un sistema de trabajo rotatorio -con turnos de siete de la mañana a tres de la tarde y de tres de la tarde a once de la noche-, que permitía ejercer un segundo empleo para incrementar los honorarios. En fin, las primas de productividad y antigüedad, las pagas extraordinarias, las ayudas familiares y los premios - puntualidad, seguridad, iniciativas, conservación de utillaje, ahorro de materiales, etc.- representaban un suplemento de entre el $10 \mathrm{y}$ el $15 \%$ del salario medio neto. Según el Departamento de Asuntos Sociales de FASA, la contratación masiva efectuada por la factoría vallisoletana y las condiciones ventajosas de las que gozaba su personal provocaron un aumento generalizado de los salarios industriales a nivel local, regional e incluso nacional ${ }^{47}$. Sin duda, estas ventajas comparativas contribuyeron a la ausencia de conflictos laborales en

\footnotetext{
${ }^{45}$ Pedrosa Sanz (1983), (1986) y (1993), y Fernández Arufe y Pedrosa Sanz (1997).

${ }^{46}$ Estos aspectos quedaron recogidos en convenios de empresa elaborados en el marco de la Ley de Convenios Colectivos de 1958. En concreto, pueden citarse el Convenio Colectivo Sindical de FASA-Renault de 27/12/1965 y el Convenio Colectivo Interprovincial de 18/3/1969, que extendía las disposiciones del primero, aplicado exclusivamente en la factoría de Valladolid, al resto de trabajadores de Renault en España. AHPV, sección Delegación Provincial de la Organización Sindical, Sindicato del Metal, caja 4618.

47 «FASA-Renault en Valladolid. Repercusiones de la implantación de la fábrica en la ciudad». AHPV, sección FASA-Renault, caja 8.
} 
la empresa durante el período abordado: en palabras de Gimeno (1993, p. 14), «si Seat estaba cada dos por tres en los periódicos por su conflictividad, FASA-Renault daba la sensación de ser una balsa de aceite». Algunos franceses, con una actitud mezcla de paternalismo y superioridad hacia España, llegaron incluso a insinuar que la implantación de Renault, amén de engendrar beneficios económicos y sociales, también había contribuido a cambiar (para mejor) la idiosincrasia española:

«L'Espagnol se couche tard, donc se lève tard; il déjeune l'après-midi vers 14 h 30 et ne dîne guère le soir avant 21 h 30 ou 22 h. Or, l'horaire pratiqué à la FASA ne ressemble en rien à ce programme. Le personnel de la FASA commence le travail le matin à 7 heures pour une journée de 8 heures interrompue seulement par une courte pause de dix minutes [...]» ${ }^{48}$.

Las consecuencias de la implantación de Renault en España y de la inyección de capital francés a partir de 1964 fueron especialmente visibles en Valladolid. Esta provincia acaparó, por sí sola, más de la mitad del volumen de la inversión industrial realizada en Castilla-León entre 1964 y 1970. Tal volumen de inversión tuvo su origen, sobre todo, en la adquisición de maquinaria y bienes de equipo por un reducido número de grandes empresas ya existentes, a la cabeza de las cuales estaba FASA-Renault ${ }^{49}$. El importante crecimiento demográfico experimentado en Valladolid durante estos años es, en su mayoría, imputable a una emigración que no puede disociarse de la contratación masiva de personal efectuada por FASA. Tampoco la expansión de la superficie urbana, que fue de un 50\% entre 1960 y 1970 . En las proximidades de la factoría vallisoletana se construyeron barrios enteros, como el de San Jerónimo, destinados a albergar a la población obrera de FASA. Dotados de todas las infraestructuras necesarias, estos barrios obreros contribuyeron a revalorizar varias zonas antes aisladas y deprimidas, lo cual actuó, probablemente, en beneficio de toda la población.

A finales de los años sesenta, Renault se había convertido en la segunda marca de automóvil en España, después de SEAT, y FASA en el tercer centro industrial de Renault en el mundo, después de Billancourt en Francia y de Haren-Vilvorde en Bélgica. En la actualidad, FASA-Renault ocupa uno de los primeros puestos en el ranking de las empresas españolas más importantes, por su cifra de negocios, inversiones, productividad y rentabilidad. Pierre Dreyfus no se equivocaba cuando en 1965 afirmó que «l'Espagne est bien l'une des plus grandes réussites de la Régie en matière d'installations à l'étranger» ${ }^{50}$.

\footnotetext{
${ }^{48}$ Renault Magazine 16 (1958, p. 19).

${ }^{49}$ Vid. Fernández Arufe y Pedrosa Sanz (1982). Las autoras se basan en las listas de «Inscripciones definitivas de nuevas industrias y ampliaciones» publicadas mensualmente por la Secretaría General Técnica del Ministerio de Industria.

${ }^{50}$ Consejo de Administración, 16/2/1965. Cfr. Loubet (2000, p. 213).
} 


\section{ALGUNAS CLAVES DEL ÉXITO DE RENAULTEN ESPAÑA}

La primera causa del éxito de Renault en España deriva del propio dinamismo de la industria automovilística, máxime en un contexto favorable de crecimiento económico. En efecto, la industria del automóvil representó uno de los focos básicos del progreso industrial en los países occidentales, no sólo por su aportación directa al producto nacional bruto, sino por su efecto multiplicador sobre las más diversas actividades económicas, al absorber enormes inputs de energía y materias primas -electricidad, acero, vidrio, caucho...-, de actividad industrial -mecánica, construcción...- y de servicios -mantenimiento, publicidad, etc. En los años cincuenta, Renault apostó por el potencial de crecimiento de la economía española y, en los sesenta, pudo recoger parte de los frutos del desarrollo experimentado en el país vecino. El slogan acuñado por FASA a principios de los sesenta - «FASA-Renault crece con España»- expresa claramente esta relación de interdependencia entre la industria del automóvil y el contexto nacional.

Pero la expansión de Renault en España no se explica únicamente por el auge de la automoción y de la economía española en los años cincuenta y, sobre todo, sesenta. También hay que aludir a los esfuerzos desplegados por el Gobierno francés para que la implantación industrial de su «empresa-piloto» en España se saldara con un éxito. Este resultado animaría a otras firmas francesas a establecer, consolidar y ampliar posiciones al otro lado de los Pirineos. Desde su nacionalización en la inmediata posguerra, la RNUR se convirtió en un fiel discípulo de la planificación indicativa francesa, un modelo de política económica que, simplificando, pretendía conjugar dirigismo y liberalismo. En este sentido, Renault siguió de cerca las recomendaciones dictadas por el Gobierno francés: superada la urgencia de la reconstrucción, los dirigentes de la IV y V República insistieron en el fomento de la exportación y de la inversión en el extranjero como requisitos necesarios para mejorar la competitividad internacional de la economía francesa. Al mismo tiempo, Renault gozó de una cierta libertad de iniciativa para seleccionar y modificar las medidas gubernamentales en función de sus propios objetivos y necesidades. En sus relaciones con España, el Gobierno y los empresarios franceses dejaron progresivamente al margen sus reticencias ideológicas hacia el régimen de Franco. Prefirieron centrarse en la dimensión económica y aprovechar el contexto favorable de crecimiento, a fin de ocupar posiciones firmes desde las que recibir a la España del futuro, previsiblemente democrática, próspera y altamente competitiva ${ }^{51}$.

Como principales estrategias para establecerse en nuestro país, las autoridades económicas francesas solían insistir en la adaptación a los condicionantes del mercado local, la concesión de espacios de gestión autónoma y el apoyo a la exporta-

\footnotetext{
${ }^{51}$ Sánchez Sánchez (2003).
} 
ción. La aplicación de estas iniciativas contribuyó de forma decisiva al éxito de la implantación de Renault en España. Esta afirmación se refuerza al conocer que buena parte de los problemas a los que tuvieron que enfrentarse otros constructores automovilísticos en España derivaron, precisamente, de la aplicación de una política rígida, que pretendió imponer, sin adaptarlos a los requerimientos locales, los procedimientos y el control de la sociedad matriz extranjera ${ }^{52}$.

\subsection{Adaptación al mercado local}

Para que tal proceso fuera viable, era preciso disponer de una amplia información sobre la evolución y características del mercado español. La Dirección General de Billancourt envió regularmente misiones de reconocimiento a España, realizó encuestas entre los asistentes a ferias, exposiciones y salones del automóvil y estudió los informes sobre la economía española que elaboraban periódicamente los diversos organismos nacionales -ministerios económicos, Comisariado del Plan, grandes bancos- e internacionales -FMI, OECE, Banco Mundial. Con esta información en la mano, la empresa francesa evaluaba las posibilidades de absorción del mercado español, la evolución de las empresas competidoras, el grado de satisfacción de los propietarios de vehículos Renault y el mercado potencial por modelo según la intención de compra y la naturaleza de la demanda-edad, sexo, profesión, poder adquisitivo, lugar de residencia, etc. A continuación, se preparaban los programas de fabricación y venta que después serían transmitidos a FASA para su aplicación.

Renault no se limitó a exportar a España los modelos fabricados en Francia, sino que los «hispanizó», es decir los adaptó a las exigencias de la clientela, a las necesidades del mercado y a las características físicas de su utilización en España. Como la RNUR en Francia, FASA se concentró en la fabricación de utilitarios de pequeño tamaño dirigidos a los habitantes de medios urbanos. No obstante, teniendo en cuenta la orografía particularmente accidentada de la Península Ibérica, las características de la red vial nacional y los hábitos del conductor local, los vehículos Renault españoles introdujeron ciertos cambios respecto a sus homólogos franceses: por ejemplo, un motor más potente, preferiblemente de tracción delantera, y unas ruedas más grandes, aptas para adaptarse al accidentado relieve de la Península y a «la costumbre española de sobrecargar los coches» ${ }^{53}$.

${ }^{52}$ Vid. el caso de Chrysler-Barreiros en García Ruiz (2001) y en García Ruiz y Santos Redondo (2001). Para explicar la «internacionalización fallida» de Chrysler en España, estos autores subrayan la falta de adaptación al mercado receptor y el excesivo control impuesto a su sociedad concesionaria, Barreiros-Diesel.

${ }^{53}$ Reunión de la Dirección. Billancourt, 8/4/1968. Archives Renault, fonds V-P, caja 34. 


\subsection{Apariencia de gestión autónoma}

Los dirigentes de la RNUR estimaron que la mejor forma de coexistir sin problemas con el resto de accionistas de FASA y con las autoridades españolas consistía en evitar que la presencia francesa fuera demasiado visible. Esta actitud facilitaría futuras compras de acciones y, sobre todo, suavizaría las posibles susceptibilidades del Gobierno español respecto a una excesiva dependencia del extranjero. Pese a la participación mayoritaria adquirida en 1964, la empresa francesa intentó adoptar una fórmula flexible que respetara, en la medida de lo posible, la estructura anterior de FASA. Para ello, limitó al mínimo indispensable el número de directivos franceses enviados a España y accedió a que los principales puestos de responsabilidad, entre ellos la Presidencia, continuaran en manos españolas. La RNUR advirtió a sus delegados que permanecieran en España sólo el tiempo necesario para formar a españoles capaces de reemplazarlos y les advirtió que, durante su estancia, guardaran una gran discreción en las manifestaciones exteriores de autoridad ${ }^{54}$.

Sin embargo, no se trataba de ceder a los españoles las riendas de Renault en España y arriesgarse, con ello, a restablecer la situación que despertó las iras de Lefaucheux en los años cincuenta. Más bien se trataba de actuar como si el control estuviera en manos españolas :

«Il faut présenter aux autorités et aux actionnaires espagnols une affaire espagnole [...] tout se passerait comme si la société espagnole avait le contrôle, comme si l'atelier était dirigé et contrôlé par le directeur de la société espagnole» ${ }^{55}$.

En realidad, la RNUR gestionó muy de cerca el funcionamiento de su filial española, gracias a la autoridad que le conferían los contratos de licencia y de asistencia técnica, y al poder de decisión que le proporcionaba su presencia mayoritaria en el Consejo de Administración. Desde mediados de los años sesenta, FASA se convirtió en una parte integrante del complejo industrial del grupo Renault y, como tal, sus movimientos dependieron, inevitablemente, de la estrategia global de la casa matriz francesa.

\subsection{Flexibilidad a la exportación}

Pese a las protestas del Gobierno español, buena parte de las empresas extranjeras establecidas en España no autorizaban a sus concesionarias la expor-

\footnotetext{
${ }^{54}$ Nota de Michel Maison, 3/11/1964. Archives Renault, fonds V-P, caja 34.

${ }^{55}$ Reunión de la Dirección. Billancourt, 28/4/1969. Archives Renault, fonds V-P, caja 34.
} 
tación a terceros países, por temor a una posible competencia en los mercados internacionales. En este sentido, Renault constituyó una excepción, puesto que, desde la concesión de su primera licencia en 1951, permitió a FASA la exportación. Ambas sociedades salieron ganando. FASA sirvió de trampolín para establecer y consolidar los vehículos Renault en los países con los que España mantenía estrechas relaciones. Así, en el transcurso de los años sesenta, las exportaciones realizadas por FASA influyeron decisivamente en la expansión de la marca Renault en varios países latinoamericanos, sobre todo en México y en Colombia, gracias al cauce de los convenios bilaterales que España mantenía con ambos países. Por su parte, FASA pudo utilizar las redes comerciales establecidas previamente por la RNUR en los cinco continentes, y también participar de las facilidades a la exportación otorgadas por el Gobierno francés a sus empresas, como los créditos y subvenciones suministrados por el Centre National du Commerce Extérieur (CNCE) o los seguros a la exportación canalizados a través de la Compagnie Française d'Assurance pour le Commerce Extérieur (COFACE).

Con el tiempo, Renault permitió también la participación de su filial española en los procesos técnicos de concepción de los nuevos modelos automovilísticos. Durante sus primeros años de funcionamiento, FASA se había limitado a recibir las piezas y documentos necesarios para ensamblar en España los modelos concebidos en Billancourt. Sin embargo, desde principios de los años setenta, adquirió plena capacidad e iniciativa para realizar sus propios estudios e investigaciones, que se saldaron con importantes resultados, como la fabricación en exclusiva del modelo Renault 7 (R-7) en 1974.

\section{CONCLUSIONES}

Si, a principios de los años cincuenta, las reticencias ideológicas hacia el régimen franquista podían obstaculizar la ejecución de operaciones extranjeras en España, en los años sesenta la realidad económica del país se antepuso a la naturaleza de su régimen político. El nacimiento industrial de Renault en España sólo fue posible gracias al concurso financiero de bancos y empresarios locales. De esta forma, sin participación accionarial ni representación administrativa de la sociedad matriz francesa, la empresa española evolucionó de forma autónoma hasta mediados de los años sesenta. El despegue aún incipiente de la economía española permitió su mantenimiento pero no su expansión, que fue el resultado directo de la inyección de capital francés que tuvo lugar a partir de 1964. Como en otros episodios de su historia contemporánea, el control extranjero, en este caso francés, fue el precio a pagar por la expansión e internacionalización de la economía española. 


\section{FUENTES}

Archivo de FASA-Renault (Valladolid).

Archivo Histórico Provincial de Valladolid (AHPV) Valladolid.

Archives Renault (Billancourt).

Archives du Ministère français de l'Industrie (Fontainebleau).

Archives du Ministère français de l'Économie, des Finances et de l'Industrie (Savigny-LeTemple).

\section{BIBLIOGRAFÍA}

Barjot, D. (dir.) (2002): Catching Up with America. Productivity Missions and the Diffusion of American Economic and Technological Influence After the Second World War. París: Presses de l’Université de Paris-Sorbonne.

Blanco Losada, J. A. (1960): «La industria automovilística en España». Información Comercial Española 326-327, pp. 211-239.

Bueno Lastra, J. y Ramos Barrado, A. (1981): La industria del automóvil en España. Madrid: Servicio de Estudios de la Bolsa de Madrid.

Carreras, A. (ed.) (1989): Estadísticas históricas de España, siglos XIX y XX. Madrid: Fundación Banco Exterior.

CatAlÁn, J. (2000): «La creación de la ventaja comparativa en la industria automovilística española, 1898-2000». Revista de Historia Industrial 8, pp. 113-155.

Cebrián, M. (2001): «La implantación comercial de Renault en España: la Sociedad Anónima Española de Automóviles Renault, 1909-1958». Comunicación presentada al VII Congreso de la Asociación Española de Historia Económica, Zaragoza, 19-21/9.

Ciuró, J. (1994): Historia del automóvil en España. Barcelona: CEAC.

De Lorenzo, A. (1962): «El mercado del automóvil en España». Información Comercial Española 350, pp. 91-105.

Dreyfus, P. (1981) : Une nationalisation réussie. París: Fayard (editado en 1977 como La liberté réussie. París: Simoën).

«Enquête: l'automobile espagnole» (1968). Entreprise 659, pp. 63-75.

FAsA-Renault (2001): Colección de vehículos fabricados en España. Valladolid: Centro Patrimonial.

Fernández Arufe, J. E. y Pedrosa Sanz, R. (1982): «Aproximación al estudio de la inversión industrial en Castilla-León (1964-1979)». Información Comercial Española 590, pp. 123-137.

— (1997): «El impacto de FASA-Renault en la economía de Castilla-León», en A. Vázquez Barquero, G. Garafolli y J. Gilly (eds.), Gran empresa y desarrollo económico. Madrid: Síntesis, pp. 215-235.

Fridenson, P. (1986): «Automobile workers in France and their work, 1914-1983», en S.L. Kaplan y C.J. Koepp (eds.), Work in France. Ithaca: Cornell University Press, pp. 514-547.

- (1997): «La 4 CV Renault», en J. Marseille (dir.), Puissances et faiblesses de la France industrielle. París: Seuil, pp. 309-323. 
García Ruiz, J. L. (2001): «Barreiros Diesel and Chrysler Corporation, 1963-1969: Causes of a Failed Internationalisation». Comunicación presentada al congreso Americanisation, Cultural Transfers in the Economic Sphere in the 20th Century. Roubaix, 20-22/9.

García Ruiz, J. L. y Santos Redondo, M. (2001): iEs un motor español! Historia empresarial de Barreiros. Madrid: Fundación Barreiros / Síntesis.

Gimeno Valledor, P. (1993): El automóvil en España: su historia y sus marcas. Madrid: Real Automóvil Club de España.

- (2002): FASA-Renault y los Renault «todo atrás» fabricados en España. Madrid: Dossat.

Gómez MendozA, A. (1990): «De la harina al automóvil: un siglo de cambio económico en Castilla y León», en J. Nadal y A. Carreras (coords.), Pautas regionales de la industrialización española. Barcelona: Ariel, pp. 159-184.

- (ed.) (2000): De mitos y milagros. El Instituto Nacional de Autarquía (1941-1963). Barcelona: Monografías de Historia Industrial.

GoRdo, M. (1995): «El automóvil, cien años de historia. De los viejos cacharros a la España del atasco». Kilómetro MAPFRE 1, pp. 24-29.

Hernández Marco, J. L. (1986): «La oferta automovilística en España antes del Seat-600, 1906-1957». Economía industrial 307, pp. 131-148.

— «[L']industrie automobile espagnole a dix ans» (1962). Amitié Franco-Espagnole 84, pp. 39-45.

LAREDo, L. A. (1983): «Santiago López González. Empresario, político y algo filántropo». Información Económica 348, pp. 5-7.

Latouille, J. y Felten, J. (1999): La guide de la 4 CV: évolution, historique, identification, conduite, utilisation, entretien. Boulogne-Billancourt: ETAI.

López Carrillo, J. M. (1998): Los orígenes de la industria de automoción en España. Madrid : Universidad Europea - CEES.

«[Un] losange sur l’Espagne» (1980). Renault Magazine 89 (octubre), pp. 31-39.

LOUBET, J. (1998): Renault: cent ans d'histoire. Boulogne-Billancourt : ETAI. (reeditado en 2000 como Renault: histoire d'une entreprise. Boulonge-Billancourt : ETAI).

Maison, M. (1996): "'La longue marche’ de Renault en Espagne, 1902-1972». Renault Histoire 8, pp. 17-27.

Manero, F. (1985): La industria en Castilla y León. Dinámica, caracteres e impacto. Valladolid : Ámbito.

Manzanares LóPez, R. (1964): «La industria del automóvil en España». Información Comercial Española 374, pp. 123-149.

«Memorias de las Juntas Generales, ordinarias y extraordinarias, de FASA-Renault». Economía Industrial (1964 a 1970, varios números).

Merlo Calvo, F. (1966): «Estructura de la industria automóvil». Economía Industrial 28, pp. 17-39.

[El] Norte de Castilla. Diario de Valladolid, 13 agosto 1953.

[El] Norte de Castilla. Diario de Valladolid, 9 marzo 1978.

Pastor Antolín, L. J.; Delgado Urrecho, J. M. y Calderón Calderón, B. (1992): Crecimiento y transformación de Valladolid, 1960-1988. Análisis de un proceso complejo y contradictorio. Valladolid: Ayuntamiento de Valladolid.

Pedrosa Sanz, R. (1983): Aproximación al estudio del capital extranjero en Castilla-León. Valladolid: Institución Cultural Simancas. 
— (1986): Capital extranjero en la industria de Castilla y León. Valladolid: Universidad de Valladolid.

— (1993): «Les effets indirects sur l'emploi de FASA-Renault à Valladolid (Espagne)», en Les effets indirects des entreprises multinationales sur l'emploi des pays d'accueil. Ginebra: Bureau International du Travail, Document de Travail n ${ }^{\circ}$ 72, pp. 98-115.

Polo García, E. (1998): Renault 4/4. Platja d’Aro: Benzina.

«Relación de los contratos aprobados por el Ministerio de Industria sobre la cesión a entidades industriales españolas de derechos de utilización de patentes y procedimientos de fabricación, transformación y conservación de productos, así como la prestación de servicios por exigencias técnicas del proceso productivo». Economía Industrial (1964 a 1970, varios números).

Renault Magazine 16 (1958, mayo), monográfico «Renault en Espagne».

Renault Magazine 75 (1972, octubre), monográfico «Pleins feux sur FASA-Renault».

Represa Rodríguez, A. y Garabito Gregorio, G. (1986): Cámara de Comercio e Industria de Valladolid. Cien años de historia, 1886-1986. Valladolid: Cámara Oficial de Comercio e Industria de Valladolid.

Rombo. Revista de FASA-Renault 1 a 7 (diciembre 1967 a diciembre 1970).

Rombo. Revista de FASA-Renault 100 (septiembre-octubre 1992), especial «FASA-Renault en 100 noticias».

SÁncheZ SÁnchez, E. M. (2003): «L’industrie française à l'heure de la modernisation économique espagnole dans les années 1960». Relations Internationales 114, pp. 231248.

SÁNCHez Soler, M. (2001): Ricos por la patria. Barcelona: Plaza \& Janés.

SAN RomÁn, E. (1995a): La industria del automóvil en España: el nacimiento de la SEAT. Madrid: Fundación Empresa Pública, Documento de Trabajo 9503.

- (1995b): «El nacimiento de la SEAT: autarquía e intervención del INI». Revista de Historia Industrial 7, pp. 141-165.

- (1999): Ejército e Industria: el nacimiento del INI. Barcelona: Crítica.

«[Les] usines de montage à l'étranger» (1959), Renault Magazine 22 (enero), pp. 20-21.

ViÑAs A. et al. (1979): Política comercial exterior de España, 1931-1975. Madrid: Banco Exterior de España, 3 vols. 
